\title{
Self-efficacy in Weight Management and Anthropometric Indices in Tehrani Male Adolescents
}

\author{
Saeid Doaei ${ }^{1,2}$, Maryam Gholamalizadeh ${ }^{*}{ }^{1}$, Elmira Karimi ${ }^{3}$, Naser Kalantari ${ }^{4}$, Alireza Mosavi Jarrahi ${ }^{5}$ \\ 1-Student Research Committee, Cancer Research Center, Shahid Beheshti University of Medical Sciences, Tehran, Iran \\ 2- Research Center of Health and Environment, Guilan University of Medical Sciences, Rasht, Iran \\ 3-Department of Nutrition, Tehran University of Medical Sciences, Tehran, Iran \\ 4-Department of Community Nutrition, School of Nutrition and Food Sciences, Shahid Beheshti University of Medical Sciences, Tehran, Iran \\ 5-Faculty of Medical School, Shahid Beheshti University of Medical Sciences, Tehran, Iran
}

\section{A B S T R A C T}

Background and Objectives: Although a growing interest on the role of self-efficacy in weight management is reported worldwide, less research has been carried out on this association in adolescents. The aim of the present study was to investigate association of weight linked self-efficacy with anthropometric measurements in Tehrani male adolescents.

Materials and Methods: The study was carried out on 535 male students aged 12-16 years old from two secondary high schools of District 5, Tehran, Iran. Weight, body mass index (BMI), body fat percentage and body muscle percentage were measured using bio impedance analyzer (BIA) scale. A validated weight efficacy lifestyle questionnaire (WEL) was used to assess weight linked self-efficacy.

Results: The higher weight linked self-efficacy was significantly associated with further body muscle percentage $(\mathrm{P}<0.05)$. However, no significant association was seen between the self-efficacy and weight, height, BMI and body fat percentage of the male adolescents.

Conclusions: Results of the current study suggest that self-efficacy for weight management may be unlinked to specific measures of obesity, while male adolescents with a higher self-efficacy in weight management may have a higher muscle mass. Further research is necessary to verify effects of self-efficacy on anthropometric indices in male adolescents.

Keywords: Male adolescent, Self-efficacy, Obesity, Anthropometric indices, Tehran

\section{Introduction}

Childhood obesity is one of the most important risk factors for comorbidities in adulthood (1). Obesity is continuously rising in children and adolescents in most high-income and low-income countries; therefore, this phenomenon is still a challenging and costly issue in health (2). The overall prevalence of obesity in 11-19 years old female and male adolescents includes 8.7 and $11.83 \%$, respectively (3). Results of a national survey on Iranian students (6-18 years old) has shown that more than one fifth of all students $(22.2 \%$ females and $22.9 \%$ males) are obese or over-weighted (4). Nearly $80 \%$ of obese adolescents are reported to be obese in adulthood (5). Recent studies have demonstrated that behavioral problems in schools such as lower self-esteem are associated to weight status in children (6-9). Recently, childhood obesity specialists have focused on multidisciplinary treatment approaches that supports long-term healthy lifestyle changes (10). Systematic reviews of child obesity treatments have revealed that multidisciplinary approaches, including nutritional intervention, physical activity program and cognitive behavioral therapy, can result in more significant decreases in bodyweight (11). Selfefficacy refers to individual conviction of being able to initiate a behavioral change required to achieve personal goals such as weight loss $(12,13)$. Weight control self-efficacy can be defined as personnal capability to make healthy eating choices for the effective weight management even when faced to 
risky environments (14). Despite the assumption that targeting increases in weight-linked self-efficacy results in enhanced weight loss, the existing studies include inconsistent and even opposite findings on roles of self-efficacy in weight management (15-23). A recent study on self-efficacy as a predictor of weight changes in 106 overweight or obese AfricanAmerican women has found that higher baseline selfefficacy includes a surprisingly reverse association with the rate of weight loss, suggesting that high initial self-efficacy may actually represent overconfidence or having less experience with weight loss attempts (21). Based on another study, higher self-efficacy included no associations with weight management in adolescents (22). Overall, results of studies on association of self-efficacy with weight management in various age groups, including male adolescents, have shown controverting and conflicting results. Furthermore, previous studies have used BMI and other anthropometric indices as primary outcomes, which may demonstrate a distorted image of healthy body weight (23). Recent studies have reported a low-level of self-efficacy in male adolescents (17-18). Therefore, the aim of the current study was to compare the weight-linked self-efficacy in male adolescents with normal weight and its association with obesity and overweight in high school students in Tehran, Iran.

\section{Materials and Methods}

\section{Participants and setting}

The present cross-sectional study was carried out in two high schools, 2015-2016, randomly selected from City District 5 of Tehran, Iran. A total number of 535 students of 12-16 years old were participated through a two-stage stratified cluster sampling design by considering inclusion criteria. The inclusion criteria consisted of lack of suffering from any weight-linked underlying diseases, no use of prescribed medications that affecting weight and lack of weight-linked diets or history of training programs in nutrition and physical activity.

\section{Ethical considerations}

The study was approved by the Ethics Committee of the National Nutrition and Food Technology Research Institute, Tehran, Iran (reference number: Ir.sbmu.nnftri.rec.1394.22). Written consents were signed by the participants and their parents before the study commencement. Benefits of participating in the study (including awareness of physical fitness and health status, free attendance to healthy lifestyle programs and receiving healthy snacks at schools) were described for the students and their parents to enhance the involvement rate of participants.

\section{Anthropometric measurements}

The anthropometric indices were measured by trained nutritionists using standard methods. Weight of students was measured using Bioimpedance Analyzer (Omron-BF511, Japan) in light clothing with no shoes. Height was measured using tape measure while standing without shoes beside wall. The body mass index (BMI) $\left(\mathrm{kg} / \mathrm{m}^{2}\right)$ was computed as weight divided by the square of height. The Z-scores of BMI were analyzed using WHO Standard BMI Chart (24). In addition to measurement of adiposity, percentages of body fat and muscle were measured using Bioimpedance Analyzer (Omron-BF511, Japan). Based on the standards, students with BMI Zscores for age of $<-2$ and $<-2-1$ SD (standard deviation) were classified as thin, BMI Z-scores for age of $\geq 1$ but $<2$ as overweight and BMI Z-scores of $\geq 2^{\text {nd }}$ percentile for age as obese. Specifically, if the Z-score of height for age was smaller than $-2 \mathrm{SD}$, the person was short-height (24). For the categorization of body composition indices, if the Z-score of body fat percentage was smaller than the $2^{\text {nd }}$ mean, the individual had low levels of body fat while when the Z-score was larger than the $91^{\text {th }}$ percentile, the individual had high levels of body fat. Individuals with low and high body muscle percentages had below $2^{\text {nd }}$ and above $98^{\text {th }}$ percentiles of body fat, respectively (19).

\section{Weight control self-efficacy}

A validated twenty-item questionnaire of selfefficacy (WEL) (25) was used to assess the selfefficacy associated to eating behaviors. This questionnaire had been used and verified to assess accurately the self-efficacy in Iranian male adolescents (20). The participants were asked to estimate their confidence in ability to avoid eating when faced with various situations such as availability of foods (e.g. 'I can control my eating on the weekends'), negative emotions (e.g. 'I can resist eating when I am anxious'), physical discomforts (e.g. 'I can resist eating when I feel physically run down'), social pressures ('I can resist eating even when I feel it's impolite to refuse others' request) and positive 
activities ('I can resist eating when I am watching TV'). Responses were measured on a scale from 0 (not confident) to 9 (very confident). Based on a previous study, total WEL scores of 20 items (0-180) for each participant were achieved from combining the numerical scores from each item and classified to above $70 \%$ as high and under $70 \%$ as low selfefficacies (26).

\section{Other measurements}

Demographics, socioeconomic status, calorie intake and physical activity were assessed to adjust their effects on associations between the major variables. The food frequency questionnaire (FFQ) was used to estimate the total energy intake and the international physical activity questionnaire (IPAQ) to estimate energy expenditure.

\section{Data analysis}

Data were analyzed using SPSS Software (PASW Statistics 23.0; SPSS Inc., Chicago, IL, USA). Subjects were categorized into three groups based on the BMI status, including under-weight, normal weight and overweight/obese groups. To test a hypothesis that self-efficacy was inversely linked to the level of obesity, multiple linear regressions were used for each dependent variable (BMI, height, weight, body fat percentage and body muscle percentage) after adjusting for age, energy intake and physical activity.

\section{Results}

Characteristics of the participants are summarized in Table 1. The average age of the adolescents was slightly more than 14 years. The mean weight of the students was $61.45 \pm 16.37$ and the mean of height was $169.33 \pm 9.84$. A majority of the student mothers had a BMI in overweight ranges and most of them were housekeepers without university educations. Nearly $55.7 \%$ of the participants $(n=298)$ were categorized into normal BMI group and 41.4\% $(n=$ 221 ) in overweight and obese groups (Table 2). Table 3 shows profiles of weight control self-efficacy within the participants. Only $19.3 \%$ of the participants were reported with high scores of the weight efficacy lifestyle questionnaire (WEL).

Table 1. Socio-demographic characteristics of the participants $(n=535)$

\begin{tabular}{llll}
\hline Demographic index & Mean (SD) & $\mathrm{N}(\%)$ \\
\hline Students' age (yr) & & $14.1(1.27)$ & \\
Students' Height $(\mathrm{cm})$ & & $169.33(9.84)$ & \\
Students' weight $(\mathrm{kg})$ & $61.45(16.37)$ & \\
Students' calorie intake (kcal) & & $2436(635)$ & \\
Students' physical activity (met) & & $979(138)$ & \\
Mothers' height (cm) & & $165.11(4.83)$ & \\
Mothers' weight $(\mathrm{kg})$ & & $79.09(32.25)$ & \\
BMI of mothers $\left(\mathrm{kg} / \mathrm{m}^{2}\right)$ & $29.02(12.54)$ & \\
& & & $113(21.1)$ \\
Number of children in the family & $2 \leq$ & & $422(78.9)$ \\
& $2>$ & & $470(87.9)$ \\
& & & $67(12.1)$ \\
Mother's employment & housekeeper & & $32(6)$ \\
& Employed & & $456(85.2)$ \\
Mother's education & & & $47(8.8)$ \\
\hline
\end{tabular}

Table 2. Descriptive statistics for the anthropometric measurements $(n=535)$

\begin{tabular}{lccc}
\hline Anthropometric index & Underweight N (\%) & normal weight & Overweight N (\%) \\
\hline Height $^{1}$ & $19(3.6)$ & $490(91.6)$ & $26(4.9)$ \\
BMI $^{2}$ & $16(3)$ & $298(55.7)$ & $221(41.4)$ \\
Body fat percentage $^{3}$ & $115(21.5)$ & $298(55.7)$ & $112(22.8)$ \\
Body muscle percentage $^{4}$ & $5(0.9)$ & $242(45.2)$ & $288(53.9)$ \\
\hline
\end{tabular}


Table 3. Self-efficacy in weight control of the participants $(n=535)$

\begin{tabular}{lll}
\hline & categories & $\mathrm{N}(\%)$ \\
\hline Self-efficacy in weight control & (Less than 70\% of the score)low & $432(80.7)$ \\
& (higher than 70\% of the score) desirable & $103(19.3)$ \\
\hline
\end{tabular}

Table 4. Regression analysis for the prediction of clinical indicators

\begin{tabular}{|c|c|c|c|c|c|c|c|c|c|c|}
\hline \multirow{2}{*}{$\begin{array}{l}\text { Anthropometric } \\
\text { indices }\end{array}$} & \multicolumn{2}{|c|}{ Weight } & \multicolumn{2}{|c|}{ Height } & \multicolumn{2}{|c|}{ BMI } & \multicolumn{2}{|c|}{ Body fat percentage } & \multicolumn{2}{|c|}{ Body muscle percentage } \\
\hline & $\begin{array}{l}\text { Beta } \\
\text { factor }\end{array}$ & $P$ value & $\begin{array}{l}\text { Beta } \\
\text { factor }\end{array}$ & $\mathrm{P}$ value & $\begin{array}{l}\text { Beta } \\
\text { factor }\end{array}$ & $\mathrm{P}$ value & $\begin{array}{l}\text { Beta } \\
\text { factor }\end{array}$ & $\mathrm{P}$ value & $\begin{array}{l}\text { Beta } \\
\text { factor }\end{array}$ & P value \\
\hline Self-efficacy & 0.02 & 0.69 & -0.01 & 0.89 & 0.01 & 0.79 & -0.04 & 0.37 & 0.14 & 0.04 \\
\hline
\end{tabular}

\section{Weight-related self-efficacy and anthropometric indices}

Results from the regression analysis showed no significant correlations between changes in BMI and changes in total score of weight-linked self-efficacy $(\mathrm{P}=0.79)$. No associations were seen between the selfefficacy and weight $(\mathrm{P}=0.69)$, height $(\mathrm{P}=0.89)$ and body fat percentage $(\mathrm{P}=0.37)$. However, changes in body muscle percentage were significantly associated with changes in WEL scores of the participants $(\mathrm{P}=0.04)$. Participants who were more confident in their ability to avoid eating in high-risk situations had higher levels of body muscle percentage.

\section{Discussion}

Results of the current study suggest that selfefficacy for weight management may be unlinked to specific measures of obesity, while male adolescents with a higher self-efficacy in weight management may have a higher muscle mass. Obese adolescents are often expected to have lower levels of weight control self-efficacy (20) and associated problems to weight management (27). The aim of the present study was to compare weight control self-efficacy schemes in normal-weight, over-weight and obese youths. Most of similar studies have focused on roles of self-efficacy in weight loss in interventional weight-loss programs (28-30). Results of the current study did not support the hypothesis of inverse relationships between the self-linked beliefs and weight, BMI and body fat percentage in school students. The fact that higher levels of self-efficacy include no meaningful links with weight, BMI and body fat percentage was unexpected because previous researches have verified self-efficacy as a significant predictor of weight loss and low-level adiposity (3135). For example, Steele and Michael investigated roles of self-efficacy in association with various measures of adiposity in early adolescent-age groups and reported that higher levels of self-efficacy was associated to lower levels of waist circumference (WC), triceps skinfold thickness (TSF) and BMI (33). Desirable eating-linked self-efficacy has been reported as a negative predictor of overweight in upper-grade elementary school students in an observational study (34). Although the existing differences may be attributed to inclusion of both males and females in these studies, the present study was carried out only on males. Moreover, the weight control self-efficacy acts in different manners in different cultural backgrounds. Cultural differences may affect correlations between the psychological factors such as self-efficacy and the anthropometric indices. Obesity may not be considered as a health problem in societies such as Iran. Furthermore, this discrepancy may occur due to the larger sample size in the present study, which has allowed for further reliable estimations.

The current results show a robust association between the weight control self-efficacy and body muscle percentage that makes this study unique for considering body composition in addition to weight and BMI for the prediction of obesity status in adolescents. It is reported that weight and BMI are not good indicators of nutritional status in adolescents (36). In other words, adolescents with higher muscle masses may mistakenly be considered as overweight or obese. Findings from the current study support this hypothesis that male adolescents with higher muscle masses have further self-efficacies in their eating habits. However, limitations in this study must be considered when extrapolating results to actual uses. The current samples included only male adolescents 
and thus results cannot be generalized to samples of female adolescents, younger children and older adults. The major strength of this study is considering body composition (as well as weight and BMI) in participants that contributes to appropriate assessment of obesity. It is not possible to verify causal associations between variables in this study due to its cross-sectional design. Another limitation includes the self-reported self-efficacy questionnaire and the possibility of inaccurate reports. Moreover, other aspects of the psychological status were not measured in this study. Despite these limitations, the current study is novel and worthy in demonstrating importance of weight management self-efficacy for the control of weight and body composition in male adolescents.

\section{Conclusion}

This study provides evidence that enhancing adolescents' confidence in their ability to resist overeating, even in face of social pressures, may improve the body muscle percentage. However, no meaningful correlations were found between the selfefficacy and weight, BMI and body fat percentage. It will be advantageous to further develop this study with a larger group of individuals, including individuals of other age and sex to achieve further reliable conclusions. Studies are also necessary to assess effects of weight linked self-efficacy on body composition in interventional weight-loss programs in various age ranges of men and women.

\section{Financial disclosure}

The authors declared no financial interest.

\section{Funding/Support}

This study was funded by the Student Research Committee of Shahid Beheshti University of Medical Sciences, Tehran, Iran (code 13162).

\section{References}

1. Kelly AS, Barlow SE, Rao G, Inge TH, Hayman LL, Steinberger J, Urbina EM, Ewing LJ, Daniels SR. Severe obesity in children and adolescents: identification, associated health risks, and treatment approaches: a scientific statement from the American Heart Association. Circulation. 2013 Oct 8;128(15):1689-712.

2. Langford R, Bonell CH, Jones H, Campbel R. Obesity prevention and thehealth promoting schools framework: essential components and barriers to success. Int $\mathbf{J}$ Behav Nutr Phys Act 2015; 12(15):1 -17.
3. Doustmohammadian A, Abdollahi M, Bondarianzadeh D, Houshiarrad A, Abtahi M. Parental determinants of overweight and obesity in Iranian adolescents: a national study. Iran J Pediatr. 2012;22(1):35-42.

4. Kelishadi R, Ardalan G, Qorbani M, Ataie-Jafari A, Bahreynian M, Taslimi M, et al. Methodology and Early Findings of the Fourth Survey of Childhood and Adolescence Surveillance and Prevention of Adult Non-Communicable Disease in Iran: The CASPIAN-IV Study. Int J Prev Med. 2013;4(12):1451-60.

5. Bodkin A. Obesity: An overview of current landscape and prevention-related activities in Ontario. Canada: Ontario Chronic Disease Prevention Alliance;2009;4(5):44-56.

6. Gholamalizadeh M, Entezari MH, Paknahad Z, Hassanzadeh A, Doaei S. The study of association between mother weight efficacy life-style with feeding practices, food groups intake and body mass index in children aged 3-6 years. International journal of preventive medicine. 2014 Jan;5(1):21.

7. Doaei S, Gholamalizadeh M, Entezari MH. Maternal selfefficacy and feeding practices in children aged 3-6 years. Iranian journal of psychiatry. 2015 Sep;10(4):278.

8. Halfon N, Larson K, Slusser W. Associations between obesity and comorbid mental health, developmental, and physical health conditions in a nationally representative sample of US children aged 10 to 17 . Acad Pediatr. 2013;13(1):6-13.

9. Wing RR. Behavioural approaches to the treatment of obesity. Handbook of obesity, clinical applications. New York: Marcel Dekker: 2004.

10 .Luca, P, Birken, C, Grewal, P, Dettmer E, Hamilton J. Complex obesity. Curr Pediatr Rev. 2012;8(2):179-187.

11. Summerbell C, Ashton V, Campbell K, Edmunds L, Kelly S, Waters E. Interventions for treating obesity in children (a review)1. Nederlands Tijdschrift Voor Evidence Based Practice. 2007;5(2), 45-46.

12. Bandura A. Self-efficacy mechanism in human agency. American Psychologist. 1982;37(2):122-47.

13.Strecher VJ, DeVellis BM, Becker MH, Rosenstock IM. The role of self-efficacy in achieving health behavior change. Health Educ Q. 1986; 13(1), 73-92.

14. Lubans DR., Plotnikoff RC, Morgan PJ, Dewar D, Costigan S, Collins CE. Explaining dietary intake in adolescent girls from disadvantaged secondary schools. A test of Social Cognitive Theory. Appetite. 2012;58(2):517-24.

15. Warziski MT, Sereika SM, Styn MA, Music E, Burke LE. Changes in self-efficacy and dietary adherence: the impact on weight loss in the PREFER study. J Behav Med. 2007;31(1):81-92.

16.Richman RM, Loughnan GT, Droulers AM, Steinbeck KS, Caterson ID. Self-efficacy in relation to eating 
behaviour among obese and non-obese women. Int $\mathrm{J}$ Obes (Lond). 2001;25(6):907-13.

17. Voelker DK, Reel JJ, Greenleaf C. Weight status and body image perceptions in adolescents: current perspectives. Adolescent health, medicine and therapeutics. 2015;6:149.

18. Edwards NM, Pettingell S, Borowsky IW. Where perception meets reality: self-perception of weight in overweight adolescents. Pediatrics. 2010 Mar 1;125(3):e452-8.19. Laurson KR, Eisenmann JC, Welk GJ. Body fat percentile curves for US children and adolescents. American journal of preventive medicine. 2011 Oct 1;41(4):S87-92.

20.Miri SF, Javadi M, Lin CY, Irandoost Kh, Rezazadeh A, Pakpou AH. Health Related Quality of Life and Weight Self-Efficacy of Life Style among Normal-Weight, Overweight and Obese Iranian Adolescents: A Case Control Study. International Journal of Pediatrics.2017;5(11):5975-84.

21.Martin PD, Dutton GR, Brantley PJ. Self-Efficacy as a Predictor of Weight Change in African-American Women. Obesity Research. 2004;12(4):646-51.

22. White MA, Martin PD, Newton RL, Walden HM, YorkCrowe EE, Gordon ST, Williamson DA, et al. . Mediators of Weight Loss in a Family-Based Intervention Presented over the Internet. Obes Res 2004; 12(7):1050-59.

23.Flattum C, Friend S, Neumark-Sztainer D, Story, M. Motivational interviewing as a component of a schoolbased obesity prevention program for adolescent girls. J Am Diet Assoc. 2009;109(1):91-94.

24. Cole TJ, Faith MS, Pietrobelli A, Heo M. What is the best measure of adiposity change in growing children: BMI, BMI\%, BMI z-score or BMI centile? European journal of clinical nutrition. 2005 Mar;59(3):419.

25. Navidian A, Abedi MR, Baghban I, Fatehizade MS, Poursharifi H. Reliability and validity of the weight efficacy lifestyle questionnaire in overweight and obese individuals. Journal of Behavioral Sciences. 2009;3(3):217-22.

26. Singh HK, Mun VL, Barua A, Ali SZ, Swee WC. Application and validation of the weight efficacy lifestyle (WEL) questionnaire among type 2 diabetes mellitus patients in Malaysia. Mal $J$ Nutr. 2018;24(3):427-40
27. Linde JA, Rothman AJ, Baldwin AS, Jeffery RW. The impact of selfefficacy on behavior change and weight change among overweight participants in a weight loss trial. Health Psychol. 2006;25:282-91.

28. Roach JB, Yadrick MK, Johnson JT, Boudreaux LJ, Forsythe WA, Billon W. Using self-efficacy to predict weight loss among young adults. J Am Diet Assoc. 2003;103(10): 1357-59.

29.Bernier M, Avard J. (1986). Self-efficacy, outcome, and attrition in a weightreduction program. Cognit. Ther. Res. 1986;10(3):319-38.

30.Presnell K, Pells J, Stout A, Musante G. Sex differences in the relation of weight loss self-efficacy, binge eating, and depressive symptoms to weight loss success in a residential obesity treatment program. Eat Behav. 2008;9(2):170-80.

31.Steele MM, Daratha KB, Bindler RC, Power TG. The relationship between self-efficacy for behaviors that promote healthy weight and clinical indicators of adiposity in a sample of early adolescents. Health Educ Behav. 2011;38(6):596-602.

32. Losekam S, Goetzky B, Kraeling S, Rief W, Hilbert A. Physical activity in normal-weight and overweight youth: Associations with weight teasing and selfefficacy. Obes Facts. 2010;3:239-44.

33. Ha SA, Lee SY, Kim KA, Seo JS, Sohn CM., Park HR, Kim KW. Eating habits, physical activity, nutrition knowledge, and self-efficacy by obesity status in uppergrade elementary school students. Nutr Res Pract. 2016;10(6):597-605.

34. Shin H, Shin J, Liu PY, Dutton GR, Abood DA, Ilich JZ. Self-efficacy improves weight loss in overweight/obese postmenopausal women during a 6-month weight loss intervention. Nutr Res. 2011;31(11):822-28.

35. Burke LE, Ewing LJ, Ye L, Styn M., Zheng Y. Music E, Sereika SM, et al. The SELF trial: A self-efficacy-based behavioral intervention trial for weight loss maintenance. Obesity. 2015;23(11):217582.

36. Kalantari N, Mohammadi NK, Rafieifar S, Eini-Zinab H, Aminifard A, Malmir H, Ashoori N, Abdi S, Gholamalizadeh M, Doaei S. Indicator for success of obesity reduction programs in adolescents: Body composition or body mass index? Evaluating a schoolbased health promotion project after 12 weeks of intervention. International journal of preventive medicine. $2017 ; 8$. 